Review

\title{
Similarities and Differences in East Asian Massage and Bodywork Therapies: A Critical Review
}

Fernando Cabo ${ }^{1, *}$, Isaac Aguaristi ${ }^{+}$

1. Barts Health NHS Trust, Margaret Centre, Whipps Cross University Hospital, Leytonstone, London, E11 1NR, United Kingdom; E-Mail: fernando.cabo@nhs.net

2. Professional Shiatsu School; E-Mail: isaacaguaristi@hotmail.co.uk

* Correspondence: Fernando Cabo; E-Mail: fernando.cabo@nhs.net

Academic Editor: Gerhard Litscher

OBM Integrative and Complementary Medicine

2020 , volume 5 , issue 1

doi:10.21926/obm.icm.2001013
Received: September 01, 2019

Accepted: March 02, 2020

Published: March 05, 2020

\begin{abstract}
Several manual bodywork therapies that originated in Asia are related to the theory and practice of acupuncture and Traditional Chinese Medicine (TCM). One of the aims of these therapies is to stimulate specific points on the body called acupoints which are the same points in which needles are inserted in acupuncture. These manual therapies, however, vary in their interpretation and explanation of the theories of TCM, and even more so, in the practical way the stimulation is applied. The aim of this paper is to clarify these differences and show how future research can benefit from specifying the actual techniques used. This paper analyses and compares research papers, textbooks, articles, official definitions and demonstrations of the techniques to highlight the similarities and differences, and examines instances in research in which the techniques were not clearly differentiated. There are many instances in the research literature in which references from one of these practices, or from acupuncture itself, has been used as evidence for other manual therapies conflating the evidence. As far as it is known, nobody has proved that inserting a needle or applying electric stimulation on a specific point on the body has the same physiological effects as pressing with a finger. Nobody has proved that applying stationary pressure has the same
\end{abstract}



(C) 2020 by the author. This is an open access article distributed under the conditions of the Creative Commons by Attribution License, which permits unrestricted use, distribution, and reproduction in any medium or format, provided the original work is correctly cited. 
effect as kneading that point. However, some research papers seem to use all these techniques interchangeably. Research would benefit from accuracy in the reporting of physiological effects of East Asian manual therapies.

\section{Keywords}

Acupuncture; bodywork; massage; Traditional Chinese Medicine

\section{Introduction}

Acupuncture is usually associated with the insertion of needles into specific points on the body. These points are normally called in the West 'acupoints'. In most cases, these points are part of a system of energy lines called meridians whose number and path, in (TCM), have evolved throughout centuries of writings on acupuncture [1].

Many types of acupuncture are based on the conceptualisation of natural laws in doctrines such as 'Yin-Yang' and 'Five elements', which are used to explain health and disease, and to choose the therapeutic approach that stipulates which acupoints have to be stimulated or sedated [2], although there are local variations in the theory and practice because of developments in different countries [3].

Other concepts used in acupuncture are the TCM concepts of energy (Qi) and blood. One should be careful with these concepts and not attribute them the same category as in Western anatomy and physiology. The concepts are not identical to its Western counterparts but include more broader aspects of function associated with different Western medical systems, as do the organs and the conceptual explanation of the 5 elements in health and disease, and the appropriate treatment according to those [4].

Several manual therapies have been related, totally or in part, to the theoretical principles of Chinese Medicine. It would, however, be a mistake to think that these therapies are similar to each other because they share some common aspects. They differ in their interpretation of the theoretical principles, and even more so in the techniques used in the practical application of the theories.

But there seems to be a lot of confusion in the research literature where many of these techniques seem to be used interchangeably [5]. This can easily be seen when using any search engine or database related to the research literature, where the search for one of these manual therapies returns research papers that use some or all of the other practices discussed in this paper as evidence for other.

By way of example, some of the papers even go as far as using the physiological effects ${ }^{1}$ of a machine as evidence of what can happen with manual therapies [6-8]. In one case, a textbook on complementary therapies [8], has an entry for shiatsu, defined as 'applying pressure mainly with hands and fingers', but gives as part of the evidence for shiatsu, a reference on the effects of a machine [9]. None of these research papers or textbooks give an explanation of why they think it is acceptable to make such a leap in their conclusions.

\footnotetext{
${ }^{1}$ In this document, the term effect(s) has been used to mean physiological effects.
} 
We believe this defies any logic, and raises many questions on the standards of research in this field. If evidence for one therapy implied evidence for another, then one needs to ask if there are truly any differences among these practices. If they are all the same, then why have different names? Why mention different techniques? Why even use different techniques if the result is the same? Are the effects of a machine the same as those of a manual therapy? All of these are valid questions that arise from what we believe is a lack of rigour in the use of references in research related to East Asian manual therapies.

This paper will examine the similarities and differences at both the theoretical and practical levels of manual oriental therapies, the different types of Anmo, its Japanese and Korean derivations, Anma, as well as Tui $\mathrm{Na}$, shiatsu, watsu and acupressure. Thai massage is briefly mentioned. It is not directly related to acupuncture or TCM, but has some aspects in common with other oriental types of massage, and some practitioners like to put them in the same category.

\section{Objectives}

The main objective of this paper is to describe and clarify the similarities and differences both at the theoretical and practical levels of East Asian manual bodywork techniques that are or have been associated with TCM and/or the theoretical aspects of acupuncture, and to question the appropriateness of using either acupuncture or one of these techniques as evidence for the effectiveness of others as found in some research papers.

It is the belief of the authors that ignoring these differences, and using different techniques interchangeably, only leads to confusion in the field of research in oriental bodywork, making it more difficult to assess the evidence. Moreover, the few studies which have addressed the question of the effects of different methods of mechanical stimulation, suggest that different types of mechanical stimulation do not have the same or similar physiological effects [10-12].

We believe not knowing which techniques were used, or how these were applied, and conflating the evidence with dissimilar practices, makes it almost impossible to attribute effects to one particular therapy. This does not mean that we deny the fact that individual differences in the method and skill of application exist when applying these techniques, but that ignoring the basics of the differences multiplies the confounding factors. This seems to have been realised as such by other researchers who have started giving more details of the interventions used in their studies [13].

We believe our approach would facilitate the analysis and description of precise details of these therapeutic interventions, as proposed in the 'CONSORT Statement for Nonpharmacologic Treatments' [14]. It would also be in line with published recommendations for writing reports on bodywork therapies research [15].

We also believe that mixing evidence for different therapies in published papers is not consistent with the rigour expected in research.

\section{Methods}

The similarities and differences have been drawn from textbooks on each of the bodywork therapies studied in this text, research papers in which individual therapies are defined or described, together with explanations and definitions from the American Organization for Bodywork Therapies of Asia (AOBTA) and publicly available videos that demonstrate those 
techniques. AOBTA is a USA-based professional association for energy-based bodywork therapies that originated in Asia and share a common Chinese Medicine foundation [16].

\subsection{Manual Therapies Related to Acupuncture and TCM: Theoretical Foundations and Practical Similarities and Differences}

Not surprisingly, Chinese massage and its Japanese and Korean derivations, are the manual therapies that are most closely related to acupuncture, TCM and its theoretical principles. The generic term for the different types of traditional Chinese massage is Anmo (or An Mo). Anmo is made up of two ideograms, 按, an, means to put the hand on, to press down with the hand, while 摩, mo, means to rub. There are, of course, many more techniques used, but these two comprise the basis of Chinese massage [17].

\subsubsection{Pu Tong An Mo}

This common type of Anmo in China is sometimes referred to as Pu Tong An Mo or general massage. It is a non-specialised type of massage that is mainly used for relaxation and is not used for the treatment of illnesses or injuries.

Theoretical Principles. A detailed knowledge of TCM or meridians medical theory is not needed to perform this massage, however, it is based on the same principles of Chinese acupuncture, and its benefits are explained as improving blood and Qi circulation as well as removing stagnant Qi and blood from muscles [17].

Techniques. Some of the techniques used are relatively similar to Swedish Massage (Classical Western Massage, although traditionally, Chinese Massage does not use oil). Both the Chinese and Western versions of general massage use some form of petrissage, although generally speaking, Swedish massage uses more whole-hand petrissage while Pu Tong An Mo tends to use a lot more the tip of the fingers and knuckles with rotating movements that work on smaller areas than Classical Western Massage [17-19]. This finger rotation technique is usually translated as rubbing. Rubbing is the main technique of the different types of Chinese Massage, it is usually done with a circular motion and it can be done with fingertips or with the base or side of the palm and forearm [17].

Implications for research. This is the only technique mentioned in this paper for which there are no implications for research, since it is not mentioned in research papers. Research papers refer to the more therapeutic form of Chinese Massage, Tui Na.

\subsubsection{Tui Na}

Also called Tui Na An Mo, it is the best known and more widespread type of TCM massage in the West and in the research literature.

It is a method of Chinese bodywork characterized by the smooth gliding or rolling movements of the hands and arms. Through Tui (push) and Na (grasp), kneading, pressing, rolling, shaking, and stretching of the body on acupoints [17].

Theoretical principles. Not surprisingly, Tui $\mathrm{Na}$ is the Chinese massage whose theoretical principles relate the most to the practice of acupuncture as done in modern China, and makes use of all the theory found in TCM. Choice of specific acupuncture points for a particular treatment 
with Tui $\mathrm{Na}$ is done according to the same principles of acupuncture using local and distant points, while diagnosis also follows the "four examinations" of TCM, observation, palpation, listening and asking and the interpretation of the results is expressed in terms of the eight patterns of disharmony (also called the eight guiding principles) [20].

The difference between Tui $\mathrm{Na}$ and acupuncture is that the latter only uses specific points while Tui $\mathrm{Na}$ uses specific points sparingly and applies more general techniques and, for obvious reasons, Tui Na concentrates on the 12 primary meridians found on the surface of the skin [21].

Techniques. Some of the basic techniques used in Tui na are also found in other types of massage, including Pu Tong An Mo and Japanese and Korean Anma. The most basic ones are kneading and rubbing. Kneading is a soft repetitive, relatively slow circular movement where the hand does not slide and which can be done with the thumb, the heel of the hand, elbow or forearm, and rubbing is a to and fro movement over the skin surface with a pace of around 100120 circles per minute [3, 21, 22].

There is a technique which is unique to Tui $\mathrm{Na}$, rolling, although the technique appears to be a relatively recent one introduced only in the 20th century [22]. Rolling is not found in any other type of massage and it consists of rolling the back of the hand over the body.

Other techniques included in Tui Na are pressing, vibration, and percussion [20-22].

Implications for research. Tui na consists of at least six different techniques. Some of them may be compared to Swedish Massage (Classical Western Massage) techniques, but, as it has been pointed out, they are not applied in the same way.

We believe research should take into account these two points. First, research papers should not use references from Swedish Massage as evidence for the acceptance or effectiveness of Tui $\mathrm{Na}$ as some papers do [23]. References 28 - 31 of this paper are used for the effectiveness of Chinese Massage therapy when neither 'Tui Na', nor 'Chinese Massage' are mentioned in the references. If it is the same as Swedish Massage, then there is no point calling it 'Tui $\mathrm{Na}^{\prime}$ or 'Chinese Massage'

And secondly, since there are so many techniques associated with Tui $\mathrm{Na}$, papers should specify which of these were used in accordance with the recommendations for reporting therapeutic massage and bodywork interventions [14, 15]. Some papers do specify the actual Tui Na techniques used [24], but others just mention Tui $\mathrm{Na}$ as if it was understood what type of intervention has been applied [23, 25]. Some, like 'Effect of Chinese massage (Tui Na) on isokinetic muscle strength in patients with knee osteoarthritis' [25], simply mention Tui Na as "the massage of soft tissue" as if this was something particular to 'Chinese Massage Therapy'.

\subsubsection{Acupressure}

Acupressure does not refer to one technique in particular, but to many. In the opinion of the authors, the overuse of references from acupressure for other studies, even other acupressure studies, is one of the biggest problems in trying to establish efficacy in oriental bodywork.

Acupressure sometimes uses bracelets that artificially and continuously press the points [2628]. Ice massage on an acupoint [29], the application of essential oils [30] or an ointment on the acupoints [31], massaging the area and applying rotating or stationary pressure on acupoints, as well as a pumping action in which the thumb repeatedly presses and releases pressure quickly are all considered acupressure [5]. There is also a branch of acupressure that only stimulates points on 
the ears called 'auricular acupressure' or 'ear-acupressure' [32]. The important thing is the stimulation of acupoints by any means, but, as far as it is known, nobody has demonstrated that stimulation by one mean is proof of efficacy or effectiveness when the stimulation is applied differently, nor that by stimulating the supposed reflex zones on the ear, the effects are the same as the stimulation of other points on the body. Hence the problem in the way these references are used.

Moreover, there is some confusion with the term 'Acupressure Massage'. Acupressure Massage can be used as any type of massage that uses Swedish Massage, Tui $\mathrm{Na}$, Thai Massage techniques or a mixture of these which includes the stimulation of some acupoints by any of these techniques [33-35].

The word 'acupressure' itself seems to have changed meaning. In the 19th century, the word meant "a procedure of placing needles in the tissue adjacent to a seriously bleeding vessel to compress the vessel and stop the bleeding" [36]

According to the Oxford dictionary and the online etymology dictionary, the modern meaning is "A form of alternative therapy in which manual pressure is used to stimulate specific points on the body along what are considered to be lines of energy" and the term originated in the 1950s [36, 37].

Most acupressure textbooks refer to self-acupressure, where the location of points is very important and the stimulation of the acupoints can be done in a variety of ways, by applying stationary or intermittent pressure, or more usually by massaging or kneading [38]. In the research literature, manual acupressure usually refers to the Tui Na technique of kneading applied to one or more acupoints by a nurse or a specialist although sometimes the 'pumping pressure' of Tui $\mathrm{Na}$ is also applied [39].

With so many different techniques given the name of acupressure, we can only say that, generally speaking, manual acupressure is mostly the application or self-application of some Tui Na techniques on acupoints.

Implications for research. It is the belief of the authors that the overuse of acupressure as a catch-all term in research papers is something that needs to be addressed. Some acupressure papers mention "the effects of acupressure on labor pain or length of labor" [40] while giving a reference for acupuncture that does not mention acupressure [41], as if the effect of the insertion of a needle could be compared to pressing with a thumb.

As evidence for the effects of electroacupuncture, other studies [42] use acupressure studies with Seabands [43], ReliefBands [44] and acupressure stimulation with a hard plastic ball fixed with a small bandage - for which the choice of point is based on Korean Acupuncture [45], while others mix the use of fingers and wristbands in the use of acupressure, assuming, without any evidence, that the effect of both is the same [46]. In 'Acupressure for prevention of pre-operative anxiety: a prospective, randomised, placebo controlled study' [47], a study with wristbands is used as evidence for the manual application of kneading acupressure [48].

It is our recommendation that references provided should be carefully checked, and realise that, although they may share the same or similar name, the techniques may differ. The effect of a machine or a wristband is not, as far as it is known, the same as the effect of a finger. In fact, the opposite seems to be the case. Manual foot massage can activate the posterior superior temporal sulcus in the brain while machine massage cannot [10]. The effect of kneading or rotating around a point is not the same as applying stationary pressure, and the effect of self-applying pressure 
cannot be used as evidence when the pressure is applied by a different person, unless studies to prove the same physiological effects are conducted.

We also believe titles and abstracts of acupressure studies should specify whether the study refers to manual acupressure, self-acupressure, wristbands or other forms of stimulation. In our opinion, all research papers on acupressure should also specify what they mean by pressure, since in some, pressure is static, while in others, pressure means kneading the point.

Acupressure itself should not be used as evidence for the effectiveness of other techniques.

\subsubsection{Anma}

Anma (sometimes spelled amma) is the Korean and Japanese pronunciation of the Chinese word for massage, An Mo. It is described by AOBTA as "a specialized form of skilled touch therapy that combines deep tissue bodywork with the application of pressure, friction, and touch to specific acu-points, superficial primary and tendino-muscle energy channels, muscles, ligaments, and joints" [49].

Not surprisingly, the theoretical construct of Anma is the same as that of Tui Na or Pu Tong An Mo using the same "classical" meridians and concept of organs found in TCM [50], although some Japanese practitioners seem to have added one more diagnostic tool not found traditionally, the diagnosis via the abdomen as developed by Shizuto Masunaga, the founder of the lokai Shiatsu Center school in Tokyo [51, 52].

In practice, Anma uses predominantly the basic techniques of Tui Na. It consists mostly of kneading and rubbing with lesser amounts of stroking and pressing [28] (pressing is called compressing in some Anma texts).

Implications for research. In the research literature, the few times the term An Mo is mentioned, it is linked to Tui Na or Chinese Massage $[25,53]$. In Japan, none of the procedures of Anma, Massage, or Shiatsu have been defined by legal acts or precedents [54], but Anma is described as mostly kneading over the clothes [50,55].

There are not many studies on Japanese Anma, but, as happens with other forms of manual therapies, some research papers on Anma [55] give references from "therapeutic massage" [56] (reference 11), as if it implied evidence for a different form of bodywork therapy.

\subsubsection{Shiatsu}

Shiatsu is a Japanese technique partly derived from Anma and developed in Japan. Shiatsu means finger pressure, and the main technique used is the application of stationary (also called sustained) pressure on different points of the body [5]. The name in Japanese means finger pressure.

Theoretical principles. There are two main schools of shiatsu from which most styles are derived, and most practitioners say they practise one or the other [5, 57-59]. Each of these two branches uses very different theoretical principles. One of the branches is named after his founder, Tokujiro Namikoshi (1905 - 2000) who developed 'Namikoshi Shiatsu' [60]. The other one is usually called in Japan 'Keiraku Shiatsu' although it is better known in the West as 'Zen shiatsu' [61]. It was founded by Shizuto Masunaga (1925 - 1981).

Namikoshi shiatsu does not use any of the language associated with acupuncture or with TCM. It explains all its actions in terms of Western anatomy and physiology [60]. However, some of the 
important points in a Namikoshi shiatsu treatment coincide with acupuncture points even if named differently. Some of these are the suprascapular point (Gallbladder 21 in TCM), the Medulla Oblongata (Governing Vessel 16), and the sanri points (large Intestine 10 on the arms and Stomach 36 on the legs) [59].

According to Alice Whieldon, who has researched the history of shiatsu extensively, and is one of the authors of the book 'Sei-Ki: Life in Resonance - The Secret Art of Shiatsu', meridians (keiraku in Japanese) were not part of shiatsu originally [62].

Masunaga, began using the concept of meridians from TCM, albeit in a different form from the standard meridians used in Tui Na or acupuncture. Masunaga created the concept of extended meridians; simply put, Masunaga's innovation consists of all meridians having a presence in the hara or abdomen, and extending the traditional arm meridians to have a presence on the legs, while the traditional leg meridians can also be found on the arms [51].

Alice Whieldon mentions that the meridian lines were not what mattered in Masunaga shiatsu. What mattered to Masunaga was meridian philosophy and not lines mapping some concrete reality. Meridians in shiatsu would have no existence outside the skilled touch of the practitioner [62].

However put, the fact that Masunaga introduced these concepts, means that others after him, wanted shiatsu to be more clearly linked to TCM. This is especially seen in "Five element shiatsu" which not only makes more use of the theoretical aspects of TCM, but it also has put more emphasis than other shiatsu styles in some of the diagnostic tools of TCM such as pulse diagnosis [63].

Techniques. Shiatsu and its practice seem to be almost unique amongst the bodywork practices mentioned so far, because it almost exclusively uses one technique, the application of pressure by leaning with the relaxed weight of the body. Shiatsu also has stretches and rotates the articulations, but the predominant technique is the application of pressure. Arguably, shiatsu is also unique because it uses exclusively the weight of the whole body in a relaxed manner when leaning to apply pressure ${ }^{2}$. The emphasis is on the word "whole". It is not just applying the weight of the body, but letting the whole body lean onto the receiver [58,64].

Tui $\mathrm{Na}$ and Anma practitioners also talk of using the weight of the body to apply pressure, but in the opinion of the authors, there are very significant and important differences, and neither Tui Na nor Anma use exclusively the weight of the body when applying pressure. This can be seen when observing the movement of the hips in videos of these different practices. The movement of the hips is more ample in shiatsu since it uses the whole body weight and does not stop the movement. One can clearly see the difference by comparing the movement of the hips and the whole body in Tui $\mathrm{Na}$ [65] [minute 3:20 to 3:36] or in Anma [66] [minute 0:11 to 0:20], to shiatsu [67] [minute 0:09 to 0:27].

These differences can also be drawn from other clues. Tui $\mathrm{Na}$ and Anma are practiced on a high massage table $[52,66,68]$ as opposed to the low table used in shiatsu $[52,69]$. Working with a higher massage table only allows to use the weight of half your body, from the waist up [66] [minute 0:22 to 0:36], unlike a low table that allows one to use the whole body [69] [minute 0:10 to $0: 17]$.

\footnotetext{
${ }^{2}$ Thai massage shares this characteristic with shiatsu, but it seems to be the only other technique that uses the whole weight of the body. Please read the entry for Thai massage.
} 
Another clue may be found in the fact that both Tui Na and Anma use pressure with the tips of three or four fingers extended holding the wrist with the other hand $[52,68]$. In shiatsu this would not be possible since it would be too unstable unless one controlled the movement of the body instead of letting go with the whole bodyweight [58].

Namikoshi and Masunaga shiatsu share three basic principles for its application [60, 70].

The use of the relaxed weight of the body to apply pressure, stationary pressure and perpendicular pressure are the three basic principles that unite all shiatsu styles. Apart from the three basic principles, all shiatsu styles apply pressure through clothing [64], use a combination of diagnosis and therapy, tools are not used, and each treatment aims to work on the whole body [71]. Taking into account what all styles of shiatsu have in common, shiatsu has been defined as " $a$ manual therapy applied by leaning forward in a relaxed manner with the weight of one's body to an optimum point, and the correct use of fingers, palms, etc., in order to apply sustained, stationary pressure on different parts of the body for the purpose of correcting the imbalances of the body, and for maintaining and promoting health. It is a holistic therapy that aims to treat most of the body in each session" [5].

It should be noted that this is a basic definition to which it can be added depending on the individual style [71].

Masunaga shiatsu adds two more basic principles, the use of mother hand and meridian continuity. Unlike Namikoshi shiatsu, which, in general, uses both hands together [59], Masunaga shiatsu uses them separately with one hand stationary, while the other applies pressure. Meridian continuity means that the whole meridian should be worked on [70].

In order to clarify how shiatsu was applied in research papers, it would be appropriate to specify not only the style or styles used, but also the techniques associated to those particular styles, and whether elements of other therapies were part of the project.

Implications for research. We believe it is not appropriate to use the definition or characteristics of one of the shiatsu styles as if they applied to the whole of shiatsu and all of the styles, as found in some research papers [72-74]. Moreover, these differences seem to pertain mostly to personal interpretations and theoretical models, and ignore the origins and development of shiatsu, when different styles have so much in common in their practical application [5, 60, 70].

Another problem in the research literature concerning shiatsu is, as in other cases, the confusion of names with the actual application. Since shiatsu in Japanese means "finger pressure", some studies seem to have equated to a certain extent shiatsu with acupressure, mixing the two as if they were similar [75]. This same study uses as evidence for shiatsu references in which "Acupressure is performed by applying consistent fingertip pressure on selected acupoints with rotational movements" (rotational movements are not part of shiatsu) [76], as well as using references that mention "press and rub" as the main technique and the application of pressure with thumb and forefinger [77]. Shiatsu does not rub nor applies pressure with thumb and forefinger at the same time, therefore, giving an acupressure reference for shiatsu may be quite inappropriate.

Again, we should point out that research would benefit from checking references properly and not accepting that relatively similar names or parts of a theoretical framework imply similarity in techniques or appropriateness in the use of one technique as evidence for another. 


\subsubsection{Watsu}

Theoretical principles and techniques. The name watsu is an abbreviation of water shiatsu. The name was coined by Harold Dull, a shiatsu therapist, who created and developed the therapy [78]. Watsu is purported to be based on the principles of Zen Shiatsu, the shiatsu style developed by Masunaga, and to be the application of shiatsu on water. It is included as a style of shiatsu by some associations [79], and some of its research studies are part of the scientific literature in shiatsu research networks [80].

In its practical application, watsu consists of a series of pulls, holds and gentle movements to a body just above the water, without any application of pressure as in shiatsu $[78,81,82]$

Some authors specifically mention the application of pressure in water $[83,84]$, although pressure cannot be applied in water since the body of the receiver would go down into the water, and neither Dull's book [78], nor any videos on watsu [81, 82] show any pressure being applied. Some researchers have pointed out how both techniques cannot be compared because there is no pressure applied in watsu [85], but others seem to assume that because the name includes shiatsu, it can be described as a shiatsu style [86], or they freely mix both techniques as if they were similar [87], or had similar effects.

Implications for research. Watsu is a clear example that, for research purposes, it is convenient not to assume that names of therapies imply clarity or similarity of what the practical application of the therapies mean. This is why it is also important to define therapies from their purely applicative point of view and not mistake theoretical explanations for technical application. Using references from a bodywork therapy, watsu, that does not use the application of pressure with the relaxed weight of the body as shiatsu, or indeed applies pressure in any other way, as evidence for the effects of shiatsu on fibromyalgia [8] seems a bit far-fetched.

\subsubsection{Machines}

The use of machines as manual bodywork in research. It might sound strange to include the use of machines in a paper about East Asian manual therapies. Nonetheless, some researchers have concluded, without any evidence to support the claim, that the effect of "massage machines" basically electric rollers that sometimes are heated - is the same as when people manipulate muscle tissue, and thus, use references of machine effects as part of the evidence for bodywork therapies.

It seems that these researchers believe the name given by the manufacturers to a particular machine is of paramount importance to know which therapy the effects of the machine have to be compared to. For instance, if a manufacturer decides to call a machine a shiatsu machine, then they compare it to shiatsu, while if another manufacturer uses a similar machine but calls it a massager, then they think it should be compared to massage. For example, a "massage chair" [88] (reference 17), is used for effects of massage, while a "shiatsu massager" which is a very similar chair, is used for effects of shiatsu $[8,89]$.

Implications for research. Saying or implying that a machine has the same effects as a manual therapy is implausible [10] and a dubious way of referencing. It seems even more improbable that the name chosen for the machine by the manufacturer has anything to do with the effects of such machine. This has not stopped researchers from using references from cases with machines as evidence for what East Asian manual therapies can cause. The case of several citations of the 
paper 'Shiatsu sympathectomy": ICA dissection associated with a shiatsu massager' [9], is the clearest example of this. It has been cited, as "proof" of the effects of shiatsu, the manual bodywork therapy, in 'Contraindications and Adverse Effects of Massage' in the book 'Complementary Therapies in Neurology: An Evidence-Based Approach' [90]. It has also been mentioned as "evidence" in research papers [6] and books [8, 89], while other studies mention it as part of "case reports of manual or mechanical massage-related injuries" as if both had the same origin or could be compared [91].

\subsubsection{Nuat Thai}

Thai massage is not related to acupuncture either in its theoretical or practical approach. It is briefly included here because it is unique alongside shiatsu in using exclusively the weight of the body to apply pressure. It would appear that this use of the body developed independently In Japan and Thailand.

Having said that, the two are different. Shiatsu consists mostly of the application of stationary pressure [5, 58, 70], while Thai massage also makes ample use of circular motion massage techniques as well as a lot of passive stretches, many of which resemble yoga postures [92, 93]. Thai massage also has "alternative walking pressure" in which pressure is applied at the same time as the palms of the hand change position one at a time, usually described as "elephant walk". Another difference is that Thai massage applies pressure at the same time as placing the body in a stretch/passive yoga position [92, 93].

\section{Conclusion}

Several East Asian manual therapies are related in one way or another to TCM, but it should be borne in mind these therapies may differ in their interpretation of the theoretical aspects of TCM and in the techniques used. The authors believe it is important to highlight the similarities and differences so as not to confuse the effects of different therapies.

Some papers in the research literature seem to take for granted that different therapies/techniques have the same effect, and are therefore valid as evidence for other therapies, when in fact there are important practical differences in their application, and, as far as it is known, nobody has tried to prove if the physiological effects are similar. It is hoped that this paper will lead to a serious discussion among researchers and reviewers on the proper use of references in relation to oriental-based manual therapies.

\section{Author Contributions}

Isaac Aguaristi searched for books and videos related to this review. The material was examined by both authors together. He also reviewed the text and suggested changes.

Fernando Cabo had the idea for the project, examined the material with Isaac Aguaristi, searched and examined research literature references and wrote the text.

\section{Funding}

All research done by the authors. 
This research did not receive any specific grant from funding agencies in the public, commercial, or not-for-profit sectors

\section{Competing Interests}

The authors have declared that no competing interests exist.

\section{References}

1. Chu JH. History of Acupuncture, in: Lin ESZ, Hsu YC. Acupunct Pain Manag. 1st ed. New York: Springer Science; 2014. pp. 3-12. doi:10.1007/978-1-4614-5275-1.

2. Loewe M. Chinese Ideas of life and death, faith, myth and reason in the Han Period (202 BCAD 220). 1st ed. London: George Allen \& Unwin; 1982. doi:10.2307/2054626.

3. Park HL, Lee HS, Shin BC, Liu JP, Shang $Q$, Yamashita $H$, et al. Traditional medicine in China, Korea, and Japan: A brief introduction and comparison. Evidence-Based Complement Altern Med. 2012; 2012. doi:10.1155/2012/429103.

4. Kaptchuk T. The Web That Has No Weaver: Understanding Chinese Medicine. 2nd ed. New York: McGraw-Hill Education; 2000. doi:10.2307/1398510.

5. Cabo F, Baskwill A, Aguaristi I, Christophe-Tchakaloff S, Guichard JP. Shiatsu and acupressure: Two different and distinct techniques. Int J Ther Massage Bodyw Res Educ Pract. 2018; 11: 4. doi:10.3822/ijtmb.v11i2.391.

6. Wada Y, Yanagihara C, Nishimura Y. Internal jugular vein thrombosis associated with shiatsu massage of the neck 2. J Neurol Neurosurg Psychiat. 2005; 76: 142-143. doi:10.1136/jnnp.2004.038521.

7. Lloyd S. Carotid artery dissection following minimal postural trauma in a firefighter. Occup Med. 2004, 54: 430-431. doi:10.1093/occmed/kqh044.

8. Ernst E, Pittler M, Wider B. Complementary Therapies for Pain Management: An EvidenceBased Approach. 1st ed. London: Elsevier Mosby; 2007.

9. Elliott MA, Taylor LP. "Shiatsu sympathectomy": ICA dissection associated with a shiatsu massager. Neurology. 2002, 58: 1302-1304. doi:10.1212/WNL.58.8.1302.

10. Li Q, Becker B, Wernicke J, Chen Y, Zhang Y, Li R, et al. Kendrick. Foot massage evokes oxytocin release and activation of orbitofrontal cortex and superior temporal sulcus, Psychoneuroendocrinology. 2018: 11: 16. doi:10.1016/j.psyneuen.2018.11.016.

11. Cambron JA, Dexheimer J, Coe P, Changes in blood pressure after various forms of therapeutic massage: A preliminary study, J Altern Complement Med. 2006; 12: 65-70. doi:10.1089/acm.2006.12.65.

12. Tachibana K, Ueki N, Uchida T, Koga H. Randomized comparison of the therapeutic effect of acupuncture, massage, and Tachibana-style-method on stiff shoulders by measuring muscle firmness, VAS, pulse, and blood pressure. Evidence-Based Complement Altern Med. 2012; 2012. doi:10.1155/2012/989705.

13. Nakano H, Kodama K, Ueda T, Mori I, Tani T, Murata S. Effect of hand and foot massage therapy on psychological factors and EEG activity in elderly people requiring long-term care: $\mathrm{A}$ randomized cross-over study. Brain Sci. 2019; 9: 54. doi:10.3390/brainsci9030054.

14. Boutron I, Moher D, Altman DG, et al. Extending the CONSORT statement to randomized trials of nonpharmacologic treatment: Explanation and elaboration, Ann Intern Med. 2008; 
148: 295-309. doi:10.7326/0003-4819-148-4-200802190-00008.

15. Munk N, Boulanger K. Adaptation of the CARE guidelines for therapeutic massage and bodywork publications: Efforts to improve the impact of case reports. Int J Ther Massage Bodyw Res Educ Pract. 2014; 7: 32-40.

16. AOBTA, ABT Definition, Scope, \& Profession. https://aobta.org/page/Def_Scope_Profession (accessed 2019 May 24).

17. Yang JM, Qigong massage: Fundamental techniques for health and relaxation. 2nd ed. Boston; YMAA; 2012.

18. Thomas S. Massage techniques: Basics of Swedish massage Video. 2008. https://www.youtube.com/watch?v=DMSXLleEf_0.

19. Chinese Massage - ASMR video. 2016. https://www.youtube.com/watch?v=b_trj2fzYNc.

20. Pritchard S. Chinese massage manual: A comprehensive, step-by-step guide to the healing art of Tui Na. 2nd ed. London: Singing Dragon; 2009.

21. Mercati M. Step-by-step Tui Na: Massage to awaken body and mind. 1st ed. London: Gaia Books; 1997.

22. Pritchard S, Tui Na: A manual of Chinese massage therapy. 1st ed. London: Churchill Livingstone; 2010. doi:10.1016/B978-0-443-06903-1.X0001-9.

23. Yang $M$, Feng $Y$, Pei $H$, Deng $S$, Wang $M$, Xiao $X$, et al. Effectiveness of Chinese massage therapy (Tui $\mathrm{Na}$ ) for chronic low back pain: Study protocol for a randomized controlled trial. Trials. 2014; 15: 418. doi:10.1186/1745-6215-15-418.

24. da Silva GD, Lorenzi-Filho G, Lage LV. Effects of yoga and the addition of tui na in patients with Fibromyalgia. J Altern Complement Med. 2007; 13: 1107-1114. doi:10.1089/acm.2007.0615.

25. Zhu Q, Li J, Fang M, Gong L, Sun W, Zhou N, Effect of Chinese massage (Tui Na) on isokinetic muscle strength in patients with knee osteoarthritis. J Tradit Chinese Med. 2016; 36: 314-320.

26. Barsoum G, Perry EP, Fraser IA. Postoperative nausea is relieved by acupressure. J R Soc Med. 1990; 83: 86-89. doi:10.1177/014107689008300209.

27. Lewis IH, Pryn SJ, Reynolds PI, Pandit UA, Wilton NCT. Effect of P6 acupressure on postoperative vomiting in children undergoing outpatient strabismus correction, $\mathrm{Br} J$ Anaesth. 1991; 67: 73-78. doi:10.1093/bja/67.1.73.

28. Nilsson I, Karlsson $\AA$, Lindgren L, Bergenheim T, Koskinen LO, Nilsson U. The efficacy of P6 acupressure with sea-band in reducing postoperative nausea and vomiting in patients undergoing craniotomy: A randomized, double-blinded, placebo-controlled study. J Neurosurg Anesthesiol. 2015; 27: 42-50. doi:10.1097/ANA.0000000000000089.

29. Naghshin N, Bokaei M, Khoshbin A, Enjezab B. Effect of ice massage on Hoku point for reduction of Labor pain. J Shahid Sadoughi Univ Med Sci. 2008; 15: 69-74.

30. Yip YB, Tse SHM. The effectiveness of relaxation acupoint stimulation and acupressure with aromatic lavender essential oil for non-specific low back pain in Hong Kong: A randomised controlled trial. Complement Ther Med. 2004; 12: 28-37. doi:10.1016/j.ctim.2003.12.003.

31. Agarwal A, Dhiraaj S, Tandon M, Singh PK, Singh U, Pawar S. Evaluation of capsaicin ointment at the Korean hand acupressure point K-D2 for prevention of postoperative nausea and vomiting. Anaesthesia. 2005; 60; 1185-1188. doi:10.1111/j.1365-2044.2005.04402.x.

32. Yang LH, Duan PB, Hou QM, Du SZ, Sun JF, Mei SJ, Wang XQ. Efficacy of auricular acupressure for chronic low back pain: A systematic review and meta-analysis of randomized controlled trials. Evidence-Based Complement Altern Med. 2017; 2017. doi:10.1155/2017/6383649. 
33. Talk M. Facial acupressure massage video. 2013. https://www.youtube.com/watch?v=ktioCfP $\mathrm{xx}-\mathrm{I}$.

34. Terrarosa2. Acupressure massage video. Australia; 2009. https://www.youtube.com/watch?v =wBZWyRZzWAs.

35. Spa JLSO. Chinese acupressure massage video. Australia; 2014. https://www.youtube.com/wa tch?v=5qnyw7ACRS4.

36. Dictionary OE. Etymology of acupressure. https://www.etymonline.com/word/acupressure (accessed 2019 January 29).

37. English Oxford Living dictionaries. Definition of acupressure in English. https://en.oxforddictionaries.com/definition/acupressure (accessed 2019 January 29).

38. Young J. Acupressure: Simple steps to health: Discover your body's powerpoints for health and relaxation. 1st ed. London: Thorsons; 2001.

39. Talbott H. Acupressure : Acupressure for the foot video. USA; 2010. https://www.youtube.co $\mathrm{m} /$ watch?v=W7NWr_Mcx3A.

40. Lee MK, Chang SB, Kang DH. Effects of SP6 acupressure on labor pain and length of delivery time in women during labor. J Altern Complement Med. 2004; 10: 959-965. doi:10.1089/acm.2004.10.959.

41. Zeisler H, Tempfer C, Mayerhofer K, Barrada M, Husslein P, Influence of acupuncture on duration of labor. Gynecol Obstet Invest. 1998; 46: 22-25. doi:10.1159/000009990.

42. Zhang $X$, Jin $H$, Fan $Y$, Lu B, Meng L, Chen JDZ, Effects and mechanisms of transcutaneous electroacupuncture on chemotherapy-induced nausea and vomiting. Evidence Based Complement Altern Med. 2014; 2014. doi:10.1155/2014/860631.

43. Alkaissi A, Evertsson K, Johnsson VA, Ofenbartl L, Kalman S. P6 acupressure may relieve nausea and vomiting after gynecological surgery: An effectiveness study in 410 women. Can J Anesth. 2002; 49: 1034. doi:10.1007/BF03017897.

44. White PF, Issioui T, Hu J, et al. Comparative efficacy of acustimulation (ReliefBand ${ }^{\circledR}$ ) versus ondansetron (Zofran ${ }^{\circledR}$ ) in combination with droperidol for preventing nausea and vomiting. Anesthesiology. 2002; 97: 1075-1081. doi:10.1097/00000542-200211000-00008.

45. Bertalanffy P, Hoerauf K, Fleischhackl R, Strasser H, Wicke F, Greher M, Gustorff B, Kober A. Korean hand acupressure for motion sickness in prehospital trauma care: A Prospective, randomized, double-blinded trial in a geriatric population. Anesth Analg. 2004; 98: 220-223. doi:10.1213/01.ANE.0000093252.56986.29.

46. Shin YH, Kim TI, Shin MS, Juon HS. Effect of acupressure on nausea and vomiting during chemotherapy cycle for Korean postoperative stomach cancer patients. Cancer Nurs. 2004; 27 : 267-274. doi:10.1097/00002820-200407000-00002.

47. Agarwal A, Ranjan R, Dhiraaj S, Lakra A, Kumar M, Singh U. Acupressure for prevention of preoperative anxiety: A prospective, randomised, placebo controlled study. Anaesthesia. 2005; 60: 978-981. doi:10.1111/j.1365-2044.2005.04332.x.

48. Agarwal A, Bose N, Gaur A, Singh U, Gupta MK, Singh D. Acupressure and ondansetron for postoperative nausea and vomiting after laparoscopic cholecystectomy. Can J Anesth. 2002; 49: 554-560. doi:10.1007/BF03017380.

49. AOBTA. Definition of Amma. https://aobta.org/page/Amma (accessed 2019 January 30).

50. Donoyama N, Satoh T, Hamano T. Effects of Anma massage therapy (Japanese massage) for gynecological cancer survivors: Study protocol for a randomized controlled trial. Trials. 2013; 
14: 233. doi:10.1186/1745-6215-14-233.

51. Archavli E. Masunaga: Renaissance Man. https://www.maga.org.il/systems/file_download.ash $x$ ?pg=259\&ver=1 (accessed 2019 January 30).

52. Mochizuki S. Anma: The art of Japanese massage, 1st ed. St Paul, MN.: Kotobuki Publications; 1995.

53. Yao Y, Zhao Y. Diseases spectrum study on pediatric TuiNa in recent 10 years. J Acupunct Tuina Sci. 2012; 10: 181-184. doi:10.1007/s11726-012-0599-4.

54. Tsutani K, Fujii R, Ogata A, Tsukayama H, Tokutake T. Evidence reports of Anma-MassageShiatsu 2011: 18 randomized controlled trials of Japan. EAMS. 2011. http://jhes.umin.ac.jp/abstract/EAMS2011E.pdf.

55. Donoyama N, Ohkoshi N, Effects of traditional Japanese massage therapy on various symptoms in patients with Parkinson's Disease: A case-series study. J Altern Complement Med. 2012; 18: 294-299. doi:10.1089/acm.2011.0148.

56. Paterson C, Allen JA, Browning M, Barlow G, Ewings P. A pilot study of therapeutic massage for people with Parkinson's disease: The added value of user involvement. Complement Ther Clin Pract. 2005; 11: 161-171. doi:10.1016/j.ctcp.2004.12.008.

57. Lardry JM. Masaje shiatsu. EMC Kinesiterapia Med Física. 2012; 33: 1-14. doi:10.1016/s12932965(12)62681-4.

58. Lundberg P. The Book of Shiatsu. London: Gaia Books; 1992.

59. Saito K. Traditional Shiatsu Therapy. 1st ed. Toronto: Shiatsu Academy of Tokyo; 2010.

60. Namikoshi T. The complete book of shiatsu therapy: Health and vitality at your fingertips. Tokyo: Japan Publications Inc; 1981.

61. Brizhik L, Chiappini E, Stefanini P, Vitiello G. Modeling meridians within the quantum field theory. J Acupunct Meridian Stud. 2019; 12: 29-36. doi:10.1016/j.jams.2018.06.009.

62. Whieldon A. Shiatsu and the Myth of Meridians. http://www.alicewhieldon.com/content/shia tsu-and-myth-meridians (accessed 2019 January 30).

63. AOBTA. Definition of five element shiatsu. https://aobta.org/page/Five_Element_Shiatsu (accessed 2019 January 30).

64. Jarmey C. Shiastu Foundation Course. 1st ed. Alresford, UK: Godsfield Press; 1999.

65. Lotusinstitute. Basic Tui Na Techniques - 基本推拿手法 Tui-na Bodywork Continuing Education Online video. 2013. https://www.youtube.com/watch?v=XBu_OaP9uSA.

66. Court X. Massage amma allongé - Extraits video. 2017. https://www.youtube.com/watch?v=p SQSgtZ3M4c.

67. Coromina A. Taller shiatsu video. 2015. https://www.youtube.com/watch?v=CfUdxsUNVdU.

68. ErrolLynch. Tuina treatment demonstration video. 2007. https://www.youtube.com/watch?v= CeHMjfnfc_E.

69. School PS. Table Shiatsu Training video; 2019. https://vimeo.com/312536207.

70. Beresford-Cooke C. Shiatsu theory and practice. 3rd ed. London: Churchill Livingstone; 2011.

71. Tsiormpatzis S. Safety and risks of shiatsu: Protocol for a systematic review. Eur J Integr Med. 2019; 28: 20-26. doi:10.1016/j.eujim.2019.03.006.

72. Brady LH, Henry K, Luth JF, et al. The effects of shiatsu on lower back pain. J Holist Nurs. 2001; 19: 57-70. doi:10.1177/089801010101900106.

73. Stevensen C. The role of shiatsu in palliative care. Complement Ther Nurs Midwifery. 1995; 1 : 51-58. doi:10.1016/S1353-6117(05)80035-6. 
74. Long AF. The potential of complementary and alternative medicine in promoting well-being and critical health literacy: A prospective, observational study of shiatsu. BMC Complement Altern Med. 2009; 9: 19. doi:10.1186/1472-6882-9-19.

75. Lanza G, Centonze SS, Destro G, et al. Shiatsu as an adjuvant therapy for depression in patients with Alzheimer's disease: A pilot study. Complement Ther Med. 2018; 38: 74-78. doi:10.1016/j.ctim.2018.04.013.

76. Hmwe NTT, Subramanian P, Tan LP, et al. The effects of acupressure on depression, anxiety and stress in patients with hemodialysis: A randomized controlled trial. Int J Nurs Stud. 2015; 52: 509-518. doi:10.1016/j.ijnurstu.2014.11.002.

77. Wu HS, Lin LC, Wu SC, Lin JG. The psychologic consequences of chronic dyspnea in chronic pulmonary obstruction disease: The effects of acupressure on depression. J Altern Complement Med. 2007; 31: 253-261. doi:10.1089/acm.2006.5342.

78. Dull H. Watsu: Freeing the body in water. 3rd ed. Bloomington, Indiana, USA: Trafford Publishing; 2004.

79. Styles of Shiatsu. Shiatsu Ther Assoc Aust. https://www.staa.org.au/Styles-of-Shiatsu (accessed 2019 March 27).

80. Shiatsu Studies. Science Library, Shiatsu Res. Netw. http://www.europeanshiatsucongress.eu/ science-library/ (accessed 2019 March 27).

81. Dull H. Harold Dull Watsu Video. USA; 2008. https://www.youtube.com/watch?v=NQ_M1ZW opTA.

82. Minakshi's Aquatic Bodywork Island Studio. Introduction to WATSU Video. USA; 2011. https://www.youtube.com/watch?v=qhq5Xvh4GYQ.

83. Schitter AM, Nedeljkovic $M$, Baur $H$, et al. Effects of passive hydrotherapy WATSU (WaterShiatsu) in the third trimester of pregnancy: results of a controlled pilot study Evidence-Based Complement Altern Med. 2015; 2015. doi:10.1155/2015/437650.

84. dos Santos Bastos G, Caetano LF. Os benefícios do Watsu na fibromialgia. Corpus et Scientia. 2010, 6.

85. Yuan SLK. Eficácia do Shiatsu na dor, sono, ansiedade, nível de confiança no equilibrio e qualidade de vida de indivíduos com fibromialgia: um ensaio clínico controlado. Universidade de São Paulo; 2012.

86. Klučinová L. Shiatsu metoda: Náhled a její možný př́nos pro fyzioterapeuty. 2010.

87. Borges RM, Parizotto NA. Análise dos efeitos fisiológicos em pacientes com estresse submetidos à técnica Watsu. Fisioterapia Brasil. 2016, 2: 33-40.

88. Posadzki P, Ernst E. The safety of massage therapy: An update of a systematic review. Focus Altern Complement Ther. 2013; 18: 27-32. doi:10.1111/fct.12007.

89. Ernst E, Pittler M, Wider B, Boddy K. Oxford Handbook of Complementary Medicine. 1st ed. Oxford: Oxford University Press; 2008.

90. Oken B. Complementary therapies in neurology: An evidence-based approach. New York: Parthenon Publishing Group; 2005.

91. Batavia M. Contraindications for therapeutic massage: Do sources agree? J Bodyw Mov Ther. 2004; 8: 48-57. doi:10.1016/S1360-8592(03)00084-6.

92. Salguero CP. Encyclopedia of Thai massage: A complete guide to traditional Thai massage therapy and acupressure. 1st ed. Findhorn, UK: Findhorn Press; 2004.

93. Mercati M. The Thai massage manual: Natural therapy for flexibility, relaxation, and energy 
balance. New York: Sterling Publishing; 2018.

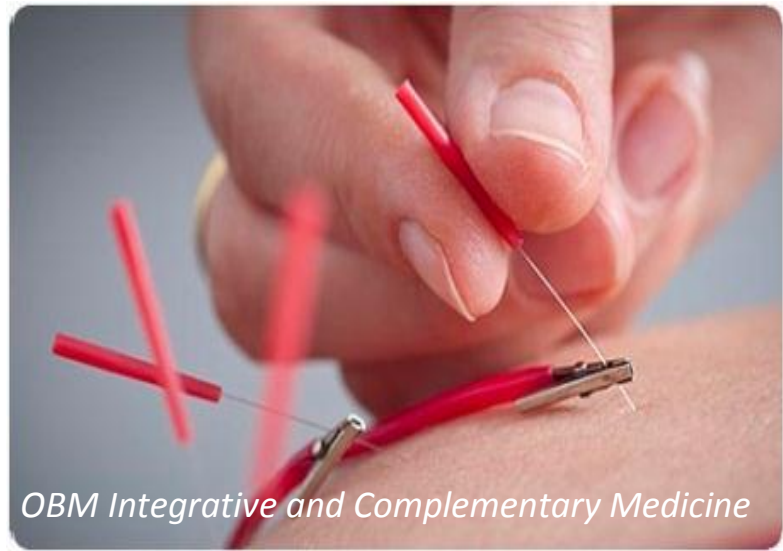

Enjoy OBM Integrative and Complementary Medicine by:

1. Submitting a manuscript

2. Joining in volunteer reviewer bank

3. Joining Editorial Board

4. Guest editing a special issue

For more details, please visit:

http://www.lidsen.com/journals/icm 